\title{
Seed germination and seedling growth of hexaploid wheat (Triticum aestivum L.) varieties as influenced by different levels of sodium chloride
}

\begin{abstract}
This experiment was conducted in the laboratory of plantation crops/Faculty of Agriculture/University Putra Malaysia in 2015 to evaluate salinity effects on seed germination percentage and some seedling growth traits of eight bread wheat cultivars and genotypes (Triticum aestivum L.). Salinity treatments were measured (0, 50, 100, 150, 200, 250 and $300 \mathrm{mM}$ sodium chloride). Distilled water was added to control treatment for each cultivar for comparison. Data regarding germination percentage, water uptake $(\%)$, plumule and radicle length $(\mathrm{cm})$, strong seed index and salt tolerance index were counted. Based on salt tolerance index, only one genotype (G8) fell in the tolerant class; three accessions (G1, G6 and G10) were moderately salt tolerant; one genotype (G2) was moderately salt susceptible and three accessions (Abo-Graib, Forat and Dijla) were salt susceptible. Results showed that increasing concentration of $\mathrm{NaCl}$ solution resulted in the gradual reduction in all studied parameters in all wheat varieties and genotypes. The G8 genotype showed significant superiority on the other genotypes and varieties in all traits above which can be used as an improved genotype against salt stress in breeding programmes, while the Abo-Graib gave the lowest rate under the probability level of significance of 0.05 . These were positively and significantly $(\mathrm{P} \leq 0.01)$ correlated between the traits studied under six concentrations $(\mathrm{mM})$ of $\mathrm{NaCl}$ stress except the relationship between germination percentage and each of water uptake, plumule length, radicle length, while strong seed index was positively but not significantly correleted. Whereas the correlation was positive and significant $(\mathrm{P} \leq 0.05)$ between water uptake and plumule length, radicle length and strong seed index.
\end{abstract}

Keyword: Germination percentage; Hexaploid wheat; Salinity; Salt tolerant index; Seedling traits 